\title{
Integrating Human Values in EFL Instruction
}

\author{
Ruwaida, Abu Rass \\ Department of English, The Academic Arab Institute for Education, Beit Berl Academic College \\ Beit Berl, 44905, Israel \\ Tel: 972-9-7476251Ｅ-mail: aburass@beitberl.ac.il
}

Received: May 15, 2014 Accepted: June 14, $2014 \quad$ Published: June 15, 2014

doi:10.5296/ijele.v2i2.5814 URL: http://dx.doi.org/10.5296/ijele.v2i2.5814

\begin{abstract}
This paper reports the results of a study that had been conducted to examine the successfulness of carrying out a project of integrating human values in EFL classrooms in two years in a row. It was part of the practical work of Arab student teachers who are majoring in Teaching English as a Foreign (EFL) in a teacher training college in Israel. The aim of including human values in EFL instruction is to qualify student teachers not only professionally and academically, but also humanly since they live in a deeply divided society which suffers also from increasing violence either at school or in the street. The project is designed to promote values that help pupils grow intellectually, morally and emotionally which eventually helps in creating a productive, healthy and peaceful society. The focus of the project is on three main values: respect, cooperation and tolerance. The project was carried out by adopting content-based instruction, problem solving and technology. Therefore, the participants integrated all language skills, included stories and folktales, showed video segments, prepared games and presented dilemmas for group discussions. The results showed that the student teachers as well as the pupils evaluated the project very positively and asked for more opportunities to extend it.
\end{abstract}

Keywords: human values, respect, tolerance, cooperation, problem-solving

\section{Introduction}

The aim of including human values in EFL instruction is to qualify student teachers not only professionally and academically, but also humanly since they live in a deeply divided society, ethnically and politically, which suffers from increasing violence either at school or in the street. The Israeli society is not only deeply divided ethnically, but also polarized economically (Kemirling, 1998). Besides the ethnic divisions, there is a lack of social solidarity among the different ethnic groups (Sagie, 2000). The divisions are witnessed not 
only between Arabs and Jews in Israel, but among the different ethnic groups in the Jewish society itself. In addition, there has a lot of tension lately in some cities in Israel between the Israeli citizens and African refugees. Therefore, there is a need for civic education in a democratic country (Adar, 2013). Civic education includes values that promote understanding, sympathy and acceptance among the members of the different ethnic groups. At the local level, Arab and Jewish students share a space by studying together in the campus, where these student teachers are trained to become English teachers. At the global context, student teachers should be well qualified to cope with the challenges of the $21^{\text {st }}$ century in terms knowledge, pedagogy, technology and multiculturalism (Tawil \& Cougoureux, 2013).

Qualifying teachers in the $21^{\text {st }}$ century according to Doler's report is based on four pillars of education: Learning to know, learning to do, learning to be and learning to live together (Tawil $\&$ Cougoureux, 2013). Learning to know is referred to mastery of learning tools as a means and an end. It means that pupils have to learn to understand the world around them, to lead their lives with dignity, develop their occupational skills and communicate with other people. Helping learners to think encompasses both practical problem-solving and abstract thought.

The second pillar is learning to do which means how to adapt education in order to equip people to do the types of work needed in the future. Personal competence is based on a body of theoretical and practical knowledge combined with personal dynamism and good problem-solving, decision-making, innovation and team skills. It also includes the needed technological skills, which means the ability to locate, assess and represent appropriate information quickly.

Learning to be includes equipping people to develop their own independent, critical way of thinking and judgment, so they can make up their minds on the best courses of action in the different circumstances in their lives. Education should enable each person to a fair-minded, responsible human being.

Learning to live together as the fourth pillar promotes cross-cultural understanding. It is expected to teach pupils and students about human diversity and to instill in them an awareness of the similarities and interdependence of all people. It requires working on projects to enable people to transcend the routines of their personal lives and attach value to what they have in common as against what divides them. Therefore, there is a need to develop curricula to introduce people to collaborative projects such as project-based learning and involvement in community activities.

Values are defined as the main beliefs that people use for determining what is right or wrong, good or bad, fair or unfair. As a result, human values such as tolerance, respect and cooperation affect people's personal perceptions and judgments, motives and actions toward others in different situations in varying cultures, societies and religions (Baba, 2011).

The project is designed to promote values that help pupils grow intellectually, morally and emotionally which eventually helps in creating a productive, healthy and peaceful society. The focus of the project is on three main values: respect, cooperation and tolerance. It aimed to improve relationships among the pupils, increase communication, create trust and enhance 
feelings of similarity among them. The student teachers worked in pairs during the intensive practical work week in a local junior high school, where they taught the same class for five days a week using materials from a book called "Learning to Live Together" which was published by UNESCO in 2008.

\section{Literature Review}

\subsection{Human Values in Education}

Human values are an important aspect in education since they determine human being behavior in society. According to Pinkley (2012), many parents and teachers acknowledge that classroom instruction of literacy and math is not enough and it should be accompanied with values that would ultimately help in producing ethical and responsible members of society. Munera, Gracia \& Lo'pez (2008) add that teachers should not care only about the academic level and improvement of their students, but also their personal growth as human beings. As a result, they will be more human (Campero, 2008) and active caring involved citizens (Shaaban, 2005).

Shaaban (2005) claims that moral education gives the students the chance "to think in informed and reflective ways about controversial moral issues" (201). In fact, he encourages moral education in pluralistic societies to educate pupils of their rights and duties, discussing differences and making informed decisions. Global human values including truth, honesty, love and sacrifice would contribute to peace and development of social ills such as fraud, oppression and apathy (Focho, 2011). Advocates of including human values in the curriculum believe that it helps learners to develop social responsibility and global citizenship (Merrifield and Kai, 2004).

Moreover, integrating values in education is considered as the transformation of the culture and life of the school (Berkowitz, 2002). For example, Schaps, Schaeffer \& McDonnell (2011) recommend involving learners in honest, thoughtful discussion and reflection in character education in terms of what they see around them, what they are told, and what do they experience and do personally. In other words, moral education would help learners develop a sense of social and personal responsibility (Shaaban, 2005). In fact, it increases the engagement and achievement of the learners because they will have the chance to identify, reflect and act upon values that would lead to a healthy society.

\subsection{Human Values in EFL Classrooms}

The idea of integrating human values in the school's curriculum has attracted the attention of ESL/EFL teachers because traditionally ESL/EFL programs strive to create better environments for people to live in at the local and global levels (Shaaban, 2005). Melouk (2007) adds that EFL competent teachers are expected to be reflective practitioners; therefore, they should look for ways to grow professionally all the time and to seek collaboration with other professionals. One way for having professional growth is to include values in EFL instruction (Coleman (2010), since they would help learners develop a sense of social and personal responsibility (Shaaban, 2005). 
Besides, English is one of the official languages of international organizations and bodies like the United Nations (UN) (Hasman, 2004). It is recommended to carry out projects that are in line with the values of such an international body for intercultural understanding and cooperation to foster global education, cross-cultural awareness, global values and critical thinking skills (Focho, 2010). In conclusion, CBI is recommended since learners not only learn language, develop values, but also have the chance to think critically (Wijaya \& Tedjaatmadja, 2009).

The findings of the research study that had been reported by Munera, Gracia \& Lo'pez (2008) show an evidence that the students found more relevant an English class with content, which is human values in this case, than in a normal English class with emphasis on language. In addition, the participants of this study showed positive reactions towards the instruction.

Pinkley (2012) states that since character education includes values, it has a place in EFL classrooms because besides language learning learners would have the opportunity to develop the learners' critical thinking skills. In fact, they are required to reflect on different situations in the daily life and express their perspectives, thoughts and feelings related to these situations (Munera, Gracia \& Lo'pez, 2008) . They add that value instruction in EFL classrooms would optimize aspects of the foreign language such as vocabulary, pronunciation, reading, writing and speaking.

However, to include value education, teachers should consider the age of the learners, their cognitive abilities and level of English (Shaaban, 2005). For example, pupils at the elementary level cannot discuss values such as using animals for research purposes; however, they could be engaged with activities that promote the value of cooperation such as taking turns, sharing, taking care of a pet, being fair and punctual (Pinkley, 2012). Similarly, activities should be selected to meet the learners' age, cognitive abilities and level of English.

Munera, Gracia \& Lo'pez (2008) mention that "factors like culture, socio-economic level, and domestic relationships should be considered when human values are implemented in an English class" (21). They also added the need for diagnosing the process before starting the instruction of human values in the English classroom. Statz (2000) adds the importance of preparing learners to think carefully and critically about moral issues.

An action research study was conducted in an English class where human values were focused by Mejia (2003) who investigated the reasons for the disruptions of some pupils and realized that economical and domestic problems were the main causes for the inappropriate classroom behaviors and the lack of the two human values: tolerance and self-esteem. Mejia (2003) declared some positive changes in the students' attitudes to their teachers and partners showing tolerance and showed interest in the workshop which gives evidence to an increase in their self-esteem.

A descriptive research study was carried out by Munera, Gracia \& Lo'pez (2008) in schools in Columbia, a country that faces a lot of social problems. Columbia is also known for increasing violence including massacres, murders and attacks on civilians (Uribe, 2005). The researchers analyzed the characteristics of the people involved in the process and their 
behavioral aspects employing multiple methods for data gathering including journals, questionnaires, interviews and video recording. The findings show positive evaluation to the integration of human values in the English classroom. In addition, they became more aware of their lives as well as their personal growth besides the significance of human values knowledge for dealing with everyday situations. Moreover, incorporating human values content in the English class gave the participants the opportunity to express themselves and their values for solving problems and to listen to their partners and to think in a reflective way, which allowed them to have better relationships with their classmates. Furthermore, it changed the routine of the class to a more enjoyable atmosphere.

Focho (2011) reports the research findings of a study that investigated the position of English in the Cameroon including English for global education. Her research reveals that by the end of the program, the participants recognized the value of global human values in an EFL setting. In addition, employing such an innovative way of teaching English increased the motivation of the learners. Focho (2011) concludes that integrating human values in EFL instruction empowers learners personally and socially.

Involving the pupils in the learning process by creating a list of discussion behaviors and rules to follow while they work in groups such: Don't interrupt, Don't talk to others, and make a poster of these agreed behaviors. It would be also useful to review the language of polite disagreement (I don't think so., I have a different opinion. I don't agree...).

\subsection{Respect, Tolerance and Cooperation}

Respect, tolerance and cooperation are three main humanistic values that promote collaboration and peaceful living as well as accepting cultural or religious diversity and individual differences Respect is an intangible but essential aspect because it is crucial to an individual's welfare and wellbeing. Moreover, it is also an important factor as far as human beings' participation and involvement within their communities' activities and affairs (Bourgois, 2002; Sennett 2003).

Tolerance also implies a willingness to tolerate disagreeable beliefs, thoughts, opinions or deeds (Rice 2009). Tolerance guarantees tolerating differences and disagreements. Being tolerant means, being able to control feelings of anger, disagreement, discomfort and dislike. It can describe feelings, attitudes and states of mind. For more decent human relations, tolerance is regarded as a precondition (Rice 2009). "Tolerance in schools needs to be taught at an early age as it can significantly help decreasing the frequency of hate crimes and racial discrimination because being aware of racial and cultural differences from a young age reduces the possibility of developing stereotypes in mixed societies" (Ford and Young, 2009, p.4 ). Cooperation is the process of working or acting together; in other words, "it is a common effort of a group for their mutual benefit"( Gintis, 2011, p.210).

Pennisi (2009) claims that people need to work together with willingness to cooperate, to help out or get involved, it means encouraging, sharing and working together. The more cooperative the group, the greater is the fitness for survival which extends to all of its members. 


\section{Recommended Methods of Instruction}

\subsection{Content-based instruction- (CBI)}

The call for incorporating human values in education has attracted the attention of many researchers and educators who prefer embedding the content in instruction and not to teach the values as a separate subject (Shaaban, 2005). Content-based instruction (CBI) is a method of teaching where language and content are combined for the purpose of language learning (Davies, 2003). It is implemented in different ways, approaches and models such as the sheltered model, adjunct, immersion and theme based. Following the theme based, content could be chosen from a very big number of different topics and relevant materials are selected for teaching the theme (Davies, 2003).The content is the values while language learning is embedded and implicit (Munera, 2008).

Addressing values could be carried out in the context of CBI through reading or literature class such as discussing stories, fables, plays and novels (Pinkley, 2012) and in history classes besides using multimedia and doing community service (Shaaban, 2005). The study of literature gives learners an insight of the different experiences of people including pleasant and sad ones in different places and times (Nord \& Haynes, 2000. Therefore, considering literature for introducing human values is recommended to deliver messages about present and future life experiences. Moreover, literary works such as fairy tales, folklore and legends are an authentic source for teaching English and have the potential for delivering values (Wijaya \& Tedjaatmadja, 2009). Furthermore, Atta-Alla (2007) recommends storytelling for integrating values in language teaching explaining that stories and storytelling language provide language learners from different linguistic and cultural backgrounds a chance to express themselves and to connect their culture to others'.

\subsection{Problem Solving Learning}

The concept of problems and problem solving was introduced by Haseli (2008). It needs the use of the target language. Following this method would develop problem solving skills and content knowledge because the pupils are required to solve a problem. When the pupils discuss the problem and are required to propose solutions, they will be active learners who have an active role as problem-solvers. According to Gvardjancic (2001), while implementing problem-based learning, learners deal with problems and learn better because they would learn what is meaningful for them and feel control of what they are learning. Vukadinovic (2003) has introduced the problem-based learning model as another type of content-based instruction where a problem is given to a group of students who are required to provide a solution, prepare a report and present the results in class. Munera, Gracia \& Lo'pez (2008) mentioned that while the participants discussed the topics presented in the problem solving activities, they had the chance to interact during the activities, reflect on some real-life circumstances and put into practice their human values besides sharing their opinions and learning about their partners. It could be concluded that the human values component in the English class was appreciated by the students and allowed the learners to increase their language proficiency mostly in pronunciation and vocabulary. 
Shaaban (2005) proposes a comprehensive framework for a project for incorporating human values in ESL/EFL programs to create active, caring and responsible citizens nationally and globally who would be agents for positive changes in modern pluralistic societies. Participants of such a program will learn English indirectly and will develop their critical thinking through problem solving learning.

\section{Incorporating Technology}

With the development of advanced technology and the growing of the social media for transcultural communication, learning English is no longer a solo academic study, it became an essential skill for world citizenship (Cummins, 2000; Melouk, 2007). As a result, ESL/EFL teachers can involve the pupils in the learning process using interesting and authentic instructional materials in an attempt to develop positive character traits, understanding and appreciation of intracultural and intercultural norms and empathy. In addition, these issues stir discussions that require the participants to think, analyze, evaluate, reflect and think critically. They also learn to express their approval and disapproval politely using specific expressions such as "I don't agree...". Furthermore, multimedia and information technology not only develop social skills but also autonomous learners.

\section{Recommended Activities}

The following recommended activities are designed to develop language and values among learners through integrating language skills such as reading strategies including skimming and scanning and speaking skills and grammatical patterns such as adjectives and adverbs (Wijaya \& Tedjaatmadja, 2009). Getting data from different sources encourages active learning through intensive student participation and interaction in open discussions (Shaaban, 2005). For example, dialogues are recommended since learners would have the chance to learn the value of conducting dialogues in terms of agreeing or disagreeing with others (Nord \& Haynes, 2000). In addition, learners are expected to read, write and deliver oral presentations.

Cooperative learning embodies values such as cooperation, sharing, respect (Shaaban, 2005). Therefore, group and pair work are highly recommended for integrating values in EFL contexts. In addition, modeling role plays of characters or figures from history or literature who could serve as models of goodness or badness, courage or cowardice is one of the most recommended activities.

Active involvement is in line with the schema theory of reading which emphasizes the role of form and content background information to enhance comprehension. Participating in community service projects, social programs, defending human rights, participating in debates, writing letters to concerned bodies and making presentations need language and knowledge. For instance, community service allows learners to participate actively, think, talk, write deliver oral presentations and participate in dialogues and discussions.

Shaaban (2005) recommends the following variant activities:

1) Identification of the characteristics of a good person or of a healthy social order 
2) Researching especially controversial issues and arguing for one position or another in an atmosphere of tolerance respecting the opinions of others

3) Viewing a movie about hot issues like euthanasia, mercy killing sources of pollution and discussing in the content in groups

4) Inviting guest speakers to talk about issues and answer questions raised by the pupils

5) Conducting mini-research papers in groups to include brainstorming, looking for sources, consulting references, choosing ideas and quotations and discussing findings in the form of presentations

6) Employing formal and informal methods of assessment to include observation checklists, dialogue journal writing, self-and peer assessment, objective tests, written essays, research papers and presenting

In addition, Pinkley (2012) proposes a number of activities such as role plays, index cards, value voting. For instance, role plays, as a fun motivating activity, could be easily designed and implemented in EFL classrooms for promoting value education. Pupils at the elementary level will deal with real situations from the outside world using specific value vocabulary. Since fables and fairy tales have moral messages, they could be easily adapted to role play activities. Older pupils would enjoy performing a dramatic scene that includes a problem or a dilemma to be solved.

The activity of index cards has also been proposed by Pinkley (2012). Cards with short problems of behavior such as seeing a friend copying during exams should be prepared while the pupils are required to judge these behaviors either by saying Right or Wrong. Six examples of such cards will be placed in an envelope and given to a pair or a group of pupils.

Value voting is a third activity proposed by Pinkley (2012); it is called listen and choose, which encourages learners to identify and choose the best behavior out of three proposed ones. For instance, teachers are expected to prepare three signs for each pair and group: one with a large letter $\mathrm{A}$, one with a large letter $\mathrm{B}$, and one with a large letter $\mathrm{C}$. A situation and three possible reactions should also be prepared and the pupils will listen and choose one of the three options: A, B or C.

Values could be expressed in creative expressions such as posters, chants and class books.. Learners could draw a picture that illustrates the learned or discussed value, sign their names and display it on the wall of the classroom. Similarly, values could be reinforced by performing chants which is an enjoyable activity. The following example of a chant would reinforce the value of helping others.

Group: $\quad$ We help others-yes, we do!

We help others. What about you?

Tell us one thing that you do!

Individual: I (help mother wash the dishes.) 
Group: $\quad$ Well, good for you! Good for you!

Older students could illustrate the learned value in a designed book to be easily accessed by others too.

\section{Method}

\subsection{Participants}

Sixteen EFL student teachers participated in this two-year study, eight ones each year. They are third year female Arab students, majoring in EFL education, which covers three areas: language competence and performance, teacher education in general and EFL pedagogy in particular. Practice teaching took place in a nearby junior high school in an Arab town in Israel, once a week throughout the year. In addition, they practiced teaching intensively twice a week. It means that they taught and observed for five days in a row. Every two formed a pair and worked together in terms of preparing the lessons and teaching them. Each couple taught one class only for five days, teaching one lesson a day, and I accompanied them in my capacity as a pedagogical adviser. To better integrating human values in their instruction, the student teachers were required to evaluate the employed activities indicating the successful activities and less successful ones.

\subsection{Procedure}

The 16 participating students were required to teach one joint lesson a day and to observe at least two lessons delivered by their classmates. For practice teaching, they were required to fill in a lesson plan sheet, which required them to describe their steps, evaluate the employed activities and to reflect on their performance mentioning which activities should and should not be used in the future and why.

Pre-lesson discussions took place in the didactic seminar course at the college which exposed them to current pedagogy as well as to methods of EFL teaching in junior high schools. In addition, post-lesson discussions for evaluation were held in the mandatory staff meetings, which were also attended by the teacher trainers, and were convened to discuss the students' preparation and practice. All lessons throughout this week were videotaped. Teaching was carried out through presenting dilemmas and asking the pupils to provide solutions. They were seated in groups, had the chance to listen to songs, watch a video segment, discuss the dilemmas, provide answers and create collages.

The participants were also required to submit a portfolio that includes their in-depth reflections on their performance at the end of the intensive practical work week besides the lesson plan sheets and observation notes.

The qualitative data sources were: (1) the portfolio at the end of the intensive practical work week that included (a) the lesson plan sheets, (2) an in-depth reflection, (3) my observation notes as a pedagogical adviser and notes that documented the discussions during the staff meetings, (4) videotaped lessons and interviews with school pupils. 


\subsection{Data Analysis}

This aim of this study was to examine the successfulness of a project that has been designed to acquaint the pupils with human values in order to help them shape their beliefs, understand others and feel sympathy with them aiming to create active and caring members of their small communities as well as the whole society.

The qualitative data were derived from the above-mentioned sources which were systematically organized, coded and indexed. Data sources were grouped by the following categories: 1) motivation and eagerness, 2) pupils' responses and interaction, and 3) employing a variety of teaching methods and activities.

In addition, the analysis of the field notes that included class observations and staff meetings followed the same categories.

\section{Results}

Over all, data analysis revealed eagerness and high motivation among the 16 student teachers. They were highly motivated to implement the project, investing joint efforts to carry out the project applying a variety of methods of teaching and including technology.

The following samples of reflections not only show their positive evaluation to the experience, but also their willingness to repeat it when they become teachers. One sentence is taken from the reflection of each participant in the two years, which are placed under the relevant category.

\subsection{Eagerness and Motivation}

a) Practicing teaching values makes me much convinced to continue teaching them; I felt the difference between teaching morals and teaching ordinary topics, when I taught values in the five lessons students were very active, they enjoyed a lot and they were enthusiastic to use the language in order to express themselves. Also the lessons were special because the suitable activities for teaching values were touching and enjoyable in the same time, they create a noticeable motive for the students to be creative, to think deeply in their morals and they understand all of the values in interesting ways.

b) The pupils interacted wonderfully in a very exciting and enthusiastic way. They said that they enjoyed the lesson a lot and that that it shed light on how important it is to be truthful and honest

c) As a trainee teacher, I felt great satisfaction and proud of myself after this practical week for having an opportunity to educate pupils not just teaching them raw material and for guiding them through different options; good and bad one.

d) Afterwards, in the practical part I tried implementing the literary discussion into the reality of the classroom by teaching lessons concerning values. The lessons were successful, fruitful and hopeful for a better future both for the pupils and for me. In my upcoming career I will undoubtedly integrate values in my lessons. 
e) The pupils showed a great interest learning about values and moral in English.

f) To be honest, not only pupils but also myself enjoyed learning/teaching about values and we both felt the difference between teaching/learning humanistic values and morals in comparison to customary teaching using the book following the current curriculum.

g) I am glad to pass the experience again... and I am sure that I am going to do so in the near future because I deeply want to develop the positive values promoting good manners among our pupils.

h) I recommend each teacher and educator to try the way we did since it was an amazing experience that I will carry on for all my life and I will never stop teaching values to my students.

i) I found it very beneficial and appropriate to the spirit of the unit that we all taught in pairs; since working in pairs requires respect, tolerance and cooperation between the partners.

\subsection{Pupils' Responses and Interaction}

a) Moreover, the pupils interacted with each other in a respectful manner by listening to each other and waiting to hear others' comments, arguments and justification of their opinion without offending other pupils due to different points of view. Argumentative techniques were provided if the pupils tried to interrupt others like: "I disagree with you but I understand what you are saying", "your opinion is different than mine but it is O.K.", "but listen to what I am trying to say" and etc. Hence, they cooperated to create a respectful and a fair discussion.

b) The pupils answered brilliantly and in a deep sophisticated way that it is a moral dilemma and that both Tom and Joe are wrong in their actions, they said that if they were unhappily married, they would just file for divorce instead of resolving to murder.

c) Each group had to come up with a reasonable solution to the dilemma that will be accepted more or less to the entire group and explain their answer to the entire class, we then discussed other possible solutions and outcomes that will be negative or positive. The pupils interacted really well since the dilemmas are realistic and can happen to them. They said they were in a real dilemma and had a hard time choosing the most suitable answer!

d) A very important observation that I will add is that indeed there are gender differences regarding toleration of others and giving respect. Whereas girls tended to listen to others more, give their classmates more time to answer, question , argue ,seemed more understanding and accepting of different opinions; boys inclined to give their answer and avoid listening to others who tried to convince them of a different perspective. Moreover, boys would just give an answer and when a classmate questions the answer back the male pupil would replay with a simple "O.K". 8) The collages were absolutely amazing and they were thrilled to create something that actually expresses their opinions. Each collage expressed the uniqueness of its group while at the same time embracing and expressing each member of the group in an individual way.

e) The collages were absolutely amazing and they were thrilled to create something that 
actually expresses their opinions. Each collage expressed the uniqueness of its group while at the same time embracing and expressing each member of the group in an individual way.

\subsection{Employing a Variety of Teaching Methods and Activities}

1) The lessons integrated many teaching techniques such as group work, activities like creating collages and short plays, games, visual aids and plenty of technology use like the online padlet (http://padlet.com/wall/74i784nejx). The lessons were meaningful and contextualized since the material was prepared to suit teenagers' way of thinking and to match their level. Moreover, the lessons intended to enrich the pupils culturally not just add words or phrases to their vocabulary. The pupils were exposed to different values like bravery and honesty, moral dilemmas that they can potentially encounter and it was interesting to see their responses.

2) The next activity was in groups where the pupils were divided to six heterogeneous groups and were given a dilemma that they have to find a solution to it. Seeing the pupils interact with each other, listening to each other and understanding different opinions and points of view really summed up the purpose of the lessons since they naturally cooperated during the activity with very little help from the teacher, they did tolerate and respect each other's' differences and communicated well.

Data analysis also revealed that the teacher trainers expressed their positive evaluation in different ways. For example, they were highly cooperative with the student teachers and eager to help in terms of photocopying and transferring the overhead projector from one room to another. They also helped the student teachers to prepare the materials for delivering the lessons. Inside the classrooms, they moved from one group to another to make sure that the pupils were working on the assignments. During the staff meetings, they were very positive indicating the significance of including values in EFL instruction, which was a new concept for them too. In addition, they were highly impressed by the hard work of the student teachers employing different methods and approaches such as CBI, group work, presenting dilemmas and integrating technology.

The videotaped lessons showed the pupils' eagerness and motivation, who were highly active and cooperative. In addition, the videotaped reflections of some pupils showed that they not only were thrilled to participate in classes, but also they cooperated very well working in groups and pairs. All in all, they highly valued the week project stating that they were exposed to human values in an interesting way and learned English at the same time.

\section{Discussion}

The purpose of the study was to examine the successfulness of implementing a project that promotes human values in an EFL context. Results showed that the student teachers were very eager and highly motivated to carry out such a project. The positive results of this study regarding the appropriateness of addressing human values in an EFL context support the claims of Pinkley (2012). Due to the successfulness of the project in general, there is a need for developing a school's curriculum that promotes values in order to create a dynamic classroom atmosphere that fosters pupils' intellectual, moral and emotional personality. Such a project 
will eventually help in creating a productive, healthy and peaceful society the way Pinkley (2012) and Munera, Gracia and Lo'pez (2008) have suggested.

The results also showed that the student teachers were very enthusiastic to implement a variety of activities and ideas for carrying out the project that emphasizes human values. It is important to note that the pupils as well as the teacher trainers at schools were very excited throughout the week when the project was implemented. The pupils not only cooperated very well with the student teachers, but also asked for more opportunities to extend it. Some of the above reflections include information about the pupils' eagerness to participate actively in the activities. These results are in line with the positive research results reported by Focho (2011), who concluded that integrating human values in EFL classrooms increased the motivation of the learners. These results match those that had been mentioned by Mejia (2003) regarding witnessing an increasing interest among the pupils in the lessons that include human values. In addition, the positive results of this study in terms of changing the routine of the class to a more enjoyable atmosphere correlate with the results that had been reported by Munera, Gracia and Lo'pez (2008).

As it has been claimed by Tawil \& Cougoureux (2013), integrating human values in education would help in qualifying teachers in the $21^{\text {st }}$ century in terms of developing content knowledge, acquainting them with current and innovative pedagogy, integrating technology and promoting multiculturalism. These claims are supported partially by the results of this study since the participating student teachers employed a variety of teaching activities and incorporated technology in their instruction.

It is important to mention that the project has been carried out in a global context through the use of the book, Learning to Live Together, which was published by UNESCO in 2008. In addition, it is based on the four pillars of Dolers report for teacher education in the $21^{\text {st }}$ century. Therefore, the student teachers not only learned the material, but also knew how to deliver it using technology to better convey the material in terms of teaching English and address human values for promoting cooperation, understanding and respect. However, promoting multiculturalism couldn't be feasible to be achieved in one week.

In addition, the student teachers invested efforts to integrate different approaches and activities in their instruction. They not only worked cooperatively creating pairs and working constantly together preparing lesson plans and teaching them in classes, but also worked as a team consulting each other and sharing materials. This shows that they practiced cooperation in their work during that week. In addition, they had a chance to implement the content-based instruction method by focusing on the theme of human values, presenting dilemmas and helping the pupils to find solutions. As Shaban (2005) says, following this method increased the engagement and the achievement of the learners, who had a chance to identify problems, solve and act them besides reflecting on their experience.

They also integrated all language skills in their instruction, included stories and folktales, and formed groups to enhance cooperation among the pupils. Incorporating technology was also obvious. Each pair made sure to show segments of videos related to the topic of human values as an authentic source of language, which were followed by different activities. 
However, since the project lasted one week only, results regarding witnessing changes in pupils' behavior in terms of showing tolerance and respect could not been noticed as it has been mentioned by Mejia (2003) and Shaban (2005).

\subsection{Conclusions, Limitations and Suggestions}

It could be concluded that the project is successful in terms of enhancing the participants' motivation, eagerness and active participation. In addition, the student teachers employed a variety of teaching methods and activities including integrating technology not only successfully, but also interestingly.

Due to the successfulness of the project in general, there is a need for developing a school's curriculum that promotes values in order to create a dynamic classroom atmosphere that fosters pupils' intellectual, moral and emotional personality, which eventually helps in creating a productive, healthy and peaceful society.

However, the project is limited in its scope in some terms. First, one week is not enough to introduce the pupils to such values and to be sure that they can instill them. At least one semester is needed to carry out such a project. There is a need to extend it to include a Jewish school in order to enhance cooperation among Jewish and Arab pupils as well as educators aiming to reduce the stereotypes against each other and hoping to promote understanding, respect, sympathy and solidarity among them. A group of EFL educators from both sectors can work together to develop a project to be carried out in four months in two schools, one in each sector. In addition, the participating pupils can also meet and do activities together. The final product could be a play which will be performed on the stage by pupils from the two schools.

\section{References}

Adar, C. (2013). What is between civic studies and civic education? A vision from inside of the formal education system. In D. Avnon (Ed.), Civic education in Israel (pp. 62-84). Tel Aviv: Am Oved. (In Hebrew).

Atta-Alla, M. N. (2007). Using storytelling to integrate faith and learning: The lived experience of Christian ESL teachers. A Journal of the International Christian Community for Teacher Education. Retrieved from http://icctejournal.org/issues/v7i2/v7u2-atta-attala/

Baba, S. (2011). Human values as common ideals and practical rules of behavior. Retrieved from http://www.saibaba-X.org.uk/4/Human_Values_as_Common_Ideals.html

Burgess, S. (2011). Deliberating through group differences in education for trust and respect. Journal of Thought, 45-61.

Coleman, H. (2010). The English language in development. London: British Council. Retrieved from www.teachingenglish.org.uk/transform.book (February 7, 2014).

Coleman, H. (2011). Allocating resources for English: The case of Indonesia's English medium international standard schools. Chapter 5. In Dreams and realities: Developing countries and the English language. Retrieved from https://www.teachingenglish.org.uk/sites/teacheng/files/Z413\%20EDB\%20Section05_0.pdf 
(Feb. 5, 2014).

Cummins, J. (2000). Biliteracy, empowerment, and transformative pedagogy. Retrieved from www.iteachilearn.com/cummins/biliteratempowerment.html (January 5, 2014).

Davies, S. (2003). Content based instruction in EFL contexts. Retrieved from http://iteslj.org/Articles/Davies-CBI.html (February 7, 2014).

Focho, G. N. (2011). Student perceptions of English as a developmental tool in Cameroon. In H. Coleman (Ed.), Dreams and realities: Developing countries and the English language (2-24). London: British Council. Retrieved from https://www.teachingenglish.org.uk/sites/teacheng/files/Z413\%20EDB\%20Section07.pdf (February 7, 2014).

Ford, A. \& Young, E. (2009). Teaching tolerance in the classroom. Retrieved from http://nyteachers.wordpress.com/2009/03/29/teaching-tolerance-in-the-classroom-by-angela-f ord-and-erin-young/ (February 7, 2014).

Giesinger, J. (2012). Respect in education: Journal of philosophy of education. Educational Studies, 46, 452-511.

Haseli, M. (2008). Two models compared: Problem-based learning and task-based learning. Retrieved from http://www.esp-world.info/Articles_8/Mehdi.html (February 5, 2014).

Hasman, M. A. (2004). The role of English in the $21^{\text {st }}$ century. TESOL Chile, 1(1), 18-22.

Kemrling, B. (1998). The new Israelies: Multiplicity of cultures without multiculturalism. Alphayem, 6, 264-308. (In Hebrew).

Mejia, P. (2003). Integrating human values with English teaching. Unpublished thesis. University of Caldas, Manizales.

Melouk, M, (2007, April). A competent EFL teacher: In search of professional standards. Paper presented in Proceedings of the $27^{\text {th }}$ MATE Annual Conference, Bouznika, Morocco.

Merrifield, M., \& Kai, M. (2004). How are teachers responding to globalization? Social Education, 68, 345-360.

Munera, J. A., Gracia, L. A., \& Lo'pez, M. T. (2008). Teaching foreign language implementing human values. University Tecnologica De Pereira, Faculty of Fine Arts Humanities Department, Licenciatura of the Teaching of English, Pereira, Colombia. Retrieved from http://repositorio.utp.edu.co/dspace/bitstream/11059/1937/1/428013A681.pdf (January 5, 2014).

Nord, W.A. and Haynes, C.C. (2000). The relationship of religion to moral education in the public schools (1).George Town University, Washington, Dc. Retrieved from www.hfni.gsehd.gwu.edu/ccps/pop_moral.html (February 12, 2014).

Pennisi, E. (2009). On the origin of cooperation, Sience, 325, 1196-1199.

Pinkely, D. (2012). Values, character, and the curriculum. Retrieved from 
http://www.pearsonlongmancom/primaryplace.pdf (February 7, 2014).

Rice, S. (2009). Education for Toleration in an era of zero tolerance school policies: A Deweyan analysis. Educational studies, 45, 556-571. http:/dx.doi.org/10.1080/00131940903338308

Sagie, A. (2006). The Israeli Jewish journey, questions about culture and identity. Shalom Heurtman Institute: Jerusalem.

Satz, D. (2000). The role of a university in a public culture. Speech to Faculty Senate at Stanford University. Retrieved from www.standford.edu/dept/EIS/satz_public_culture.html (February 7, 2014).

Sennett, R. (2004). Education for respect in a new time. Educational studies, 45, 556-571. http://dx.doi.org/ 10.1080/00131940903338308

UNESCO. (2008). Learning to live together: An intercultural and interfaith programme for ethics education. Geneva: UNESCO Headquarters.

Veugelers, V. (2000). Different ways of teaching values. Educational Review, 52(1), 37-46.

Wijaya, H. S., \& Tedjaamadja, H. M. (2009). Fairy-tales: The integration of values and language skills in teaching. Retrieved from http://www.researchgate.net/publication/43649621_Fairy-tales_The_Integration_of_Values_a nd_Language_Skills_in_Teaching (January 5, 2014).

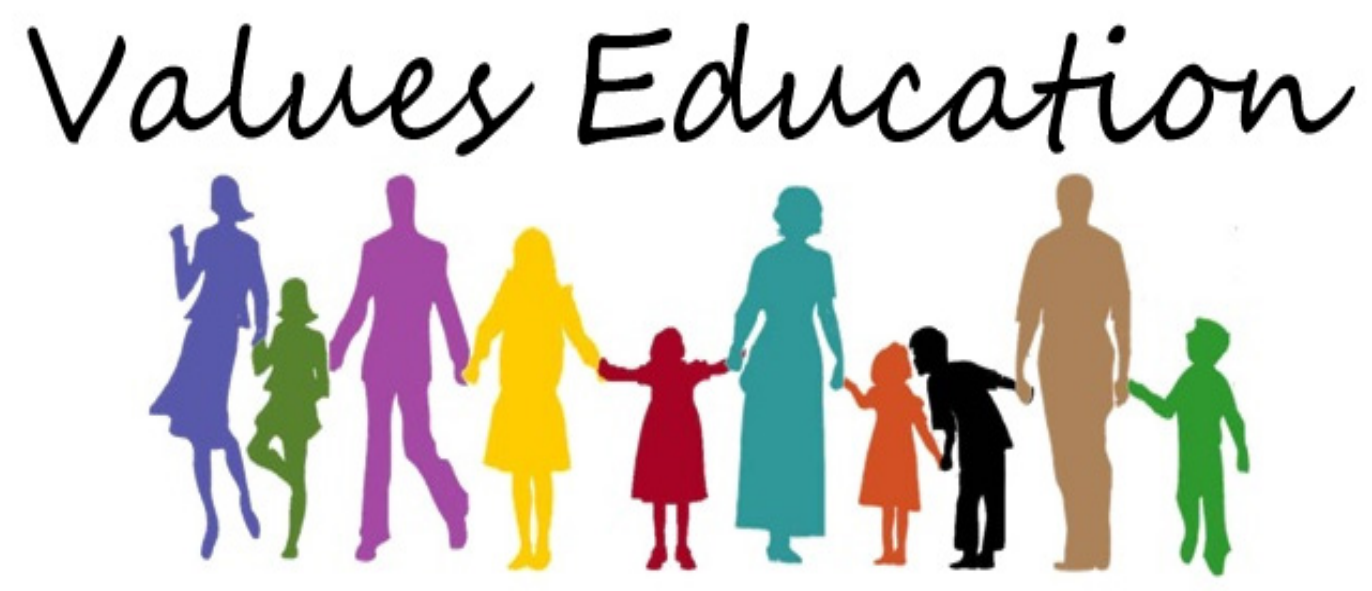

\section{Copyright Disclaimer}

Copyright reserved by the author(s).

This article is an open-access article distributed under the terms and conditions of the Creative Commons Attribution license (http://creativecommons.org/licenses/by/3.0/). 